\title{
CARTA ABIERTA A FRANCISCO MÁRQUEZ VILLANUEVA
}

\author{
Bernard Vincent*
}

\section{Estimado amigo:}

En su amabilísima carta, empieza dándome las gracias por la atención prestada a sus trabajos. Esta atención no es obviamente otra cosa que lo debido a una empresa científica que hace reflexionar sobre problemas de suma importancia. Y en estas páginas busco simplemente prolongar el diálogo que su iniciativa propone, iniciativa que, no lo puedo esconder, me ha alegrado enormemente. Formulo deseos para que nuestros intercambios sean aclaratorios de nuestras posturas e interpretaciones y sean útiles para la comunidad de investigadores interesada por esta materia y, por qué no, para todos los ciudadanos preocupados por las relaciones entre hombres de creencias y de formaciones distintas.

Es necesario primero explicar unas palabras cuyo empleo ha provocado posibles malentendidos. Usted está sorprendido ante mi declaración de que "el problema morisco sea de naturaleza histórica y no literaria".

Creo no haber dicho eso. En ningún momento he tenido la pretensión de hacer del tema morisco un coto reservado al historiador. Como usted, estoy convencido de que muchos tipos de documentos pueden ser útiles a la historia de los moriscos, "un fragmento de cerámica, un testimonio pictórico, un texto literario o una cultura antropológica, etc...", como lo son para cualquier otra parcela de la historia de la humanidad. Y en ningún momento he querido establecer una jerarquía que hubiera dado al documento archivístico un lugar eminente y al documento impreso un papel menor. No hago ninguna diferencia en su utilización y, por ejemplo, admiro profundamente Los moriscos del reino de Granada de Julio Caro Baroja, libro que fue probablemente elaborado sin que don Julio hubiera entrado en un archivo ${ }^{1}$. No cabe duda de que los progresos en el campo tan complejo, tan rico y tan comprometido del estudio de las minorías resultan de las aportaciones de especialistas que pertenecen a disciplinas y a culturas distintas, y de las confrontaciones entre ellas.

Retomo, pues, la frase tal como figura en El río morisco: "la cuestión morisca es, ante todo, un problema histórico, el de la existencia de una comunidad

\footnotetext{
* École des Hautes Études en Sciences Sociales, Paris.

1. Julio Caro Baroja, Los moriscos del reino de Granada, Madrid, Instituto de Estudios Políticos, 1957.
} 
que vivió en el territorio español en un tiempo preciso (1502-1609)"'2. Mantengo hoy esta formulación con una corrección o con un añadido: obviamente la historia de los moriscos no termina con su expulsión de España. ¿Pero qué quise decir cuando redacté esta frase?

Dos cosas cuya mezcla es tal vez la causa del malentendido. Quería primero recomendar el uso de todos los documentos, incluso los emitidos por la Inquisición y los demás consejos de la realeza. He visto en su brillante expresión de las fuentes envenenadas una condena de los esfuerzos de los historiadores que habían recurrido con precauciones a este tipo de documentos. Quise subrayar que el investigador bien formado y atento no se deja engañar por los prejuicios o las mentiras de un inquisidor o de un secretario. Y me preocuparon las consecuencias de su comentario a "las fuentes envenenadas" porque una lectura extremada de sus consideraciones puede inducir al abandono de las fuentes inquisitoriales. La necesaria crítica de ellas no ha sido siempre acompañada de la de otras fuentes ${ }^{3}$. Los protocolos notariales, así, están presentados demasiado rápidamente como el lugar donde está revelada la verdadera naturaleza de las relaciones entre moriscos y cristianos viejos. En otro trabajo he dedicado algunas páginas al asunto con el objeto de recordar que las fuentes notariales (obviamente enriquecedoras) están, como todas las demás, llenas de veneno ${ }^{4}$. Pero después de leer su carta creo que estamos ya en cuanto a uso de fuentes y a la interdisciplinariedad, como se dice, totalmente de acuerdo.

Si con mi frase buscaba reflexionar a partir de un reproche dirigido a buena parte de una generación de investigadores del tema morisco, intentaba también, en el marco de un indispensable cruce de fuentes, recordar el principio básico de la necesaria contextualización del documento, principio que me ha parecido estar a veces insuficientemente contemplado por los especialistas de la literatura. Tenemos que estar siempre muy atentos al momento y al lugar de emisión del documento. Podemos tomar el ejemplo de los siete cuadros que representan los episodios de la expulsión de los moriscos del Reino de Valencia. Su autoría y su realización quedaron desconocidas hasta el descubrimiento por Jesús Villalmanzo Gameno de los órdenes de pago a los pintores Pere Oromig, Vicent Mestre, Jerónimo Espinosa y Francisco Peralta ${ }^{5}$. Sabemos así que por encargo de Felipe III los artistas ejecutaron los lienzos en 1612-

2. El río morisco.

3. Encontramos una larga e interesante reflexión sobre el manejo de las fuentes, principalmente inquisitoriales y notariales, en el capítulo I del libro de Amalia García PedrazA, Actitudes ante la muerte en la Granada del siglo XVI. Los moriscos que quisieron salvarse, Granada, Universidad de Granada, 2002. El título del capítulo es «La vida religiosa de los moriscos granadinos. ¿Sólo una historia de criptoislamismo?».

4. Convivencia difícil en Santiago CASTILlo y Pedro OLIVER (coords.), Las figuras del desorden, heterodoxos, proscritos y marginados, Madrid, Siglo XXI, 2006, pp. 57-80.

5. La expulsión de los moriscos del reino de Granada, Valencia, Fundación Bancaja, 1977. 
1613, antes de que fuera acabada la expulsión en otros territorios de España. Las interpretaciones que podemos dar del conjunto de los cuadros dependen en parte de aquel momento tan significativo. No podrían ser las mismas si Felipe IV hubiera sido el promotor de la empresa y no su padre.

El examen de la literatura aplicada a los moriscos, sea aljamiada, sea maurófila, no debe escapar a la exigencia de la criba temporal y espacial. Nuestro acercamiento al Abencerraje no puede ser el mismo que a Ricote y menos aún a Marcos de Obregón o al Tuzaní de Calderón. No es idéntico ser maurófilo en 1570, en 1645, 1618 o en 1633. Y si efectivamente el despliegue de la maurofilia literaria es amplio ya en el siglo XVI y a principios del XVII, ésta presta entonces poca atención al hecho morisco en sí mismo. Sus personajes evolucionan en su mayoría en el mundo inmediatamente anterior a 1492, tanto Abindarráez como los Zegríes y Abencerrajes, Ozmín y Daraja o Álvaro Tarfe. Los finalmente pocos héroes propiamente moriscos de la literatura, principalmente Ricote y el Tuzaní, vieron la luz después de la expulsión. La segunda parte de las Guerras Civiles de Granada, terminada en 1597, no fue publicada antes de 1619, como subrayó María Soledad Carrasco Urgoiti ${ }^{6}$. De esta forma, ninguno ha podido tener influencia sobre el debate acerca de la suerte reservada a los moriscos.

Y en cuanto a mi apreciación de la literatura aljamiada, reconozco que la fórmula "poca cosa" es excesiva porque esta literatura constituye un capítulo original e interesante de los estudios moriscos. Pero no comparto el énfasis con el cual la ha considerado Álvaro Galmés de Fuentes. Al aspecto cuantitativo se añade un contenido reiterativo, salvo en el caso del Mancebo de Arévalo, verdadera joya que es a la literatura aljamiada lo que representa el Quijote para la literatura universal. De hecho hoy, a pesar de los esfuerzos de los equipos asturiano, madrileño, puertorriqueño y de otros investigadores, este campo se renueva poco. Quizás, como tantas veces en nuestros dominios, es una situación pasajera. Pero, sin grandes hallazgos recientes, el panorama es poco alentador. Los mismos especialistas no son optimistas.

Y una vez más conviene preguntarse a qué época pertenecen los textos aljamiados. Los comentarios que hizo Míkel de Epalza al respecto hace veinte años merecen ser meditados ${ }^{7}$. Subrayaba que tanto el léxico como la métrica de los poemas o sus temas narrativos corresponden al siglo XV o a los principios del XVI. Concluía que la llamada literatura aljamiado-morisca está repartida en

6. María Soledad CARrasco Urgoiti, El moro de Granada en la literatura, Revista de Occidente, Madrid, 1956, nueva edición con estudio preliminar de Juan MARTínez RuIZ, Granada, Universidad de Granada, 1989. Ver de la misma autora, Los moriscos y Gines Pérez de Hita, Barcelona, Bellaterra, 2006.

7. Míkel de EPALZA, «Le lexique religieux des Morisques et la littérature aljamiado-morisque», en Louis Cardaillac (ed.), Les Morisques et l'Inquisition, Paris, Publisud, 1990, pp. 55 y 57. Hay que precisar que Antonio Vespertino Rodríguez piensa que una parte de los manuscritos aljamiados datan de la segunda mitad del XVI. Sin embargo, las consideraciones de Míkel de Epalza me parecen convincentes. 
dos bloques: el del aljamiado anterior a 1525 y el del alfabeto latino, después de la expulsión. Está en medio "el periodo morisco u inquisitorial, para el cual quedan textos fragmentarios o tradicionales, textos redactados por cristianos viejos sobre las creencias islámicas o textos de moriscos muy cristianizados". En estas circunstancias la literatura aljamiada no sería la voz de los moriscos españoles que tanto apuntó Álvaro Galmés de Fuentes, sino principalmente la voz de los mudéjares y la voz de los moriscos exiliados de habla castellana. Personalmente, veo más huellas de las voces moriscas en el siglo XVI, en Francisco Núñez Muley, Miguel de Luna y Alonso del Castillo, Ginés Pérez de Hita o Ignacio de las Casas.

En El río morisco, no me paré mucho en el mito del morisco inasimilable porque en el fondo comparto su visión de este aspecto. Y puse el acento en lo que diferenciaba la interpretación de Álvaro Galmés de Fuentes de la suya al respecto. Pero me recuerda usted en su carta que el blanco de su argumento no era Galmés de Fuentes sino Braudel. Me ha incitado a mirar detenidamente todo lo que el profesor del Collège de France ha escrito sobre los moriscos y el papel que les atribuye en la difusión del mito. La descalificación consecuente de su trabajo me parece excesiva, por no decir injusta. Voy a intentar dar una interpretación ponderada de sus páginas después de haber precisado que nunca he sido alumno de Fernand Braudel (sí de Pierre Vilar ique no era particularmente su mejor amigo!). El haber leído y releído toda su obra y el haber podido acercarme a él en varias ocasiones me permiten, al menos así creo, hacer comentarios oportunos.

Glosar el famoso artículo de Braudel, «Espagnols et morisques», publicado en 1947, las páginas "moriscas" del Méditerranée de la primera edición francesa de 1949, de la segunda de 1966 y de las traducciones al castellano de 1953 y 1967 no es tarea fácil. Puede haber distorsiones entre el original y la traducción. Eso ocurre precisamente con la cita de la nota 8 de su carta abierta. Braudel escribe "la religion a été le prétexte autant que la cause de ses persécutions", poniendo pretexto y causa al mismo nivel, mientras que la versión española da más peso al pretexto que a la causa'. No es naturalmente lo mismo, y posiblemente Braudel no ha prestado suficiente atención a la traducción.

Usted, estimado amigo, considera que Braudel es indeferente a los aspectos intelectuales y que elimina virtualmente el factor humano al frente de la historia. Me permitirá matizar bastante esta opinión. Basta para darse cuenta de que no es ajeno al papel del individuo en la historia con leer sus sugestivas

8. Para la figura de Miguel de Luna ver Mercedes GARCíA AREnAl y Fernando RodríGUEz MEDIANO, «Miguel de Luna, cristiano arábigo de Granada», en Manuel BARRIOS AGUILERA y Mercedes GarcíA-Arenal (eds.), ¿La historia inventada? Los libros plúmbeos y el legado sacromontano Granada, Fundación el legado Andalusí, 2008, pp. 83-136.

9. Fernand BRAUDEL, La Méditerranée et le monde méditerranéen à l'époque de Philippe II, Paris, Armand Colin, 1949, p. 357. 
biografías de Carlos V y de Felipe II que ha dado para una editorial italiana en 1965 y $1969^{10}$. Él mismo me comentó que tenía poca simpatía por Felipe II y que se sentía mucho más atraído por la figura de Carlos V. Por otra parte, sus fuertes vínculos con Lucien Febvre y con Marcel Bataillon le conducían a no olvidar la importancia de los aspectos intelectuales.

Braudel tenía, eso sí, dificultad en pensar el mundo religioso. En La Méditerranée el concilio de Trento apenas está presente. Un día subrayé esta carencia delante de su esposa, quien dio como explicación la formación profundamente laica del historiador. Este rasgo ha influido probablemente en su acercamiento al tema morisco. Braudel estuvo sobre todo muy marcado por su estancia en Argel entre 1923 y 1930 y su descubrimiento del hecho colonial. Hombre de su tiempo, ve a los moriscos como un cuerpo extraño, de ahí el título significativo del artículo de Annales de 1947: «Españoles y Moriscos». Un cuerpo que se puede tachar fácilmente de inasimilable.

Hay dos Braudel frente a la cuestión morisca. Por un lado el heredero del colonialismo francés para quien el morisco es inasimilable. Emplea la palabra dos veces. A la cita que figura en la nota 10 de su carta hay que añadir algo que no está en el artículo de 1947 pero sí en las dos versiones de La Méditerranée: “A l'autre bout de la Méditerranée, les Espagnols étaient, eux aussi, aux prises avec un de ces peuples inassimilables et prennent la chose au tragique. En profondeur peu de problèmes ont travaillé autant que celui-là la Péninsule"11. En 1966 Braudel corrige ligeramente «un peuple inassimilable», prueba de la importancia que da a la expresión. Por otro lado está el Braudel fino observador de las realidades y consciente de los matices. Insiste por ejemplo sobre la importancia de los matrimonios mixtos, sobre el dominio desigual de la lengua árabe entre los moriscos, etc.

Creo que es este segundo Braudel el que ha dejado huella en los estudios moriscos posteriores. El de la inasimilación ha tenido poco eco. De hecho encontramos muy pocas referencias a ella en la historiografía. Y por una razón sencilla. Cuando en 1947 o en 1949 escribe sus páginas no se aparta en este punto de la percepción decimonónica. Los lectores de los años 1950 ó 1960 han retenido de él lo que representaba una ruptura con lo anteriormente escrito. Y la insistencia braudeliana en la diversidad de los problemas moriscos, que tanto contradecía el carácter inasimilable de los nuevamente convertidos, era, perdóneme, novedad. Es cierto que Cervantes había ilustrado perfectamente esta diversidad ¿pero quién en 1947 recurría a Cervantes para hablar de los moriscos? El España en su historia de don Américo es de 1948. Luego Castro y Braudel se han ignorado. Lo podemos lamentar, obviamente.

10. Las dos biografías han sido luego traducidas al francés en Fernand BRAUDEL, Ecrits sur l'Histoire, Paris, Arthaud, 1990, tomo II, pp. 171-257.

11. F. BRAudel, La Méditerranée et le monde méditerranéen à l'époque de Philippe II, ed. de 1949, ed. de 1966, tomo II, p. 118. 
La validez del modelo braudeliano del mundo morisco plural no se ha agotado. A partir de sus premisas estamos forzados a plantearnos la cuestión peliaguda y decisiva del perfil mayoritario de los moriscos en distintas fechas y particularmente en 1609. Usted me recuerda la presentación que hace Cervantes de la familia de Ricote, que reúne en su seno tres posturas distintas. Desde luego las tres existían a principios del siglo XVII, pero ¿cuál era dominante entre los moriscos de la época? Si durante dos o tres décadas (años 19501980) el principal objetivo de la investigación de los historiadores fue el colectivo, éste ha sido posteriormente relegado a un segundo plano. La atención que prestan ahora los estudiosos a las trayectorias y a las creencias de los individuos facilita el encuentro entre especialistas de la literatura y especialistas de otros documentos escritos. Pero por muy legítima y muy enriquecedora que sea, hace correr el peligro de la diseminación, del esparcimiento. Si no queremos caer en una confusa colección de casos tenemos que examinar la relación individuo-colectivo intuida por Braudel. ¿Quién es el más representativo de un grupo, de una comunidad, Ricote, Ana Félix o Juan Tiopieyo? ¿Cuál es el grado de asimilación, o, a la inversa, del cripto-islam de Ricote, de Ana Félix, de Juan Tiopieyo; de los moriscos de Almagro, del Campo de Criptana o de Almagro; de los de la Mancha, de Aragón o del reino de Valencia? ¿Y cuáles son los criterios que nos permiten medir la asimilación o el cripto-islam?

Braudel ha tenido pues una influencia positiva con este modelo del mundo morisco plural. Y tiene otro mérito que usted mismo reconoce. Retomo textualmente su cita, proveniente del artículo de 1947: "se rechaza el planteamiento hasta entonces dominante de enjuiciar si España salió ganando o perdiendo con la expulsión, o si en esto obró bien o mal moralmente. El único sentido legítimo del problema se centra en comprender por qué se hizo así"12. Si la respuesta de Braudel no le satisface, tenemos que admitir que todavía hoy la pregunta no ha perdido vigencia. Aquel artículo de 1947, con todos sus elementos discutibles, es desde luego el primer trabajo de la era del tema morisco en el cual estamos todavía inscritos. Sin él y sin el magisterio de su autor, Tulio Halperin Donghi no hubiera emprendido su investigación sobre los moriscos del reino de Valencia y probablemente Henri Lapeyre no hubiera escrito Géographie de l'Espagne morisque, editada en una colección dirigida por Braudel ${ }^{13}$. Y aún en 1977 el autor de La Méditerranée se interesó por los moriscos, haciendo un prefacio al libro de Louis Cardaillac, Morisques et Chrétiens, un affrontement polémique ${ }^{14}$. No le podemos

12. Francisco MÁrquez VillanueVa, El problema morisco (desde otras laderas), Madrid, Libertarias, 1991, p. 129.

13. Tulio Halperin DONGHI, Un conflicto nacional, Moriscos y cristianos viejos en Valencia, Valencia, Universidades de Valencia, Granada y Zaragoza, 2008, con una nueva introducción del autor. La primera versión completa de este trabajo se publicó en la revista Cuadernos de Historia de España, 1955, pp. 5-115 y 1957, pp. 83-250. Henri LAPEYRE, Géographie de l'Espagne morisque, Paris, S.E.V.P.E.N, 1959.

14. Louis CARDAILLAC, Morisques et chrétiens, un affrontement polémique (1492-1640), Paris, Klincksieck, 1977. 
negar una larga atención, que llegó hasta las aspectos religiosos en principio tan alejados de sus inquietudes, y una fecunda preocupación por los aspectos socioeconómicos que tendemos hoy demasiado a abandonar.

Seré mucho más breve acerca del segundo mito que estuvo detectando en la historiografía, el del complot permanente de los moriscos. El mito conspiratorio -como el mito del morisco inasimilable- estaba en la mente de muchos de los cristianos viejos del siglo XVI. Aquí radica el desfase que existe entre la realidad de los hechos y la construcción de los imaginarios. Del lado de la realidad no hay que menospreciar las numerosas formas de resistencia activa, las más de las veces violentas, de los moriscos (operaciones de monfies, ayuda a empresas corsarias, revueltas o conatos de revueltas). Fueron suficientemente reiterativas para entretejer un clima de inquietud en buena parte de la sociedad viejo-cristiana. Este clima es notablemente palpable después de la rebelión de las Alpujarras de 15681570. Es impresionante comprobar hasta qué punto la sublevación de los moriscos ha marcado los espíritus hasta el momento de la expulsión. Se pueden acumular centenares de referencias que indican el verdadero pavor que suscita el recuerdo del acontecimiento. Sobre esta base cualquier rumor puede tomar cuerpo como en el caso de la ¿conspiración? de Sevilla de $1580^{15}$.

Sabemos nosotros que en ningún momento el sultán otomano pensó en colaborar decididamente con los moriscos. Tenemos la ventaja de conocer los pormenores y el desenlace de la tragedia, pero ni los moriscos ni los cristianos viejos podían adivinarlos. A través de unos indicios tenues, unos contactos, unas cartas, unas profecías, los unos y los otros creían en una posible enorme operación que hubiera reunido a otomanos, berberiscos y moriscos. Se veía también a los moriscos en el centro de una conspiración urdida con la ayuda de los protestantes franceses o de los portugueses partidarios del Prior de Crato. El mito conspiratorio es una construcción de los hombres del siglo XVI, no de los historiadores del XIX o del XX.

El potencial conspiratorio que se prestaba a los moriscos no ha sido nunca suficientemente valorado. Con la rebelión (es el término exacto, muy bien elegido por Mármol Carvajal, que se debe utilizar) de 1568, han sumado al delito de herejía el de traición. Son malos españoles que han tomado las armas contra su rey y que son capaces de volver a hacerlo. En el Archivo General de Simancas abundan, en vísperas de la decisión de expulsión, los avisos de la organización de un complot, aquí o allá.

Tenemos que trabajar sobre la representación del peligro morisco entre 1570 y 1610, sobre su difusión y sobre su eventual manipulación. Es difícil saber si Felipe III o Lerma daban crédito a los avisos que recibían, pero el tema del peligro amenazando a la monarquía está presente en los bandos de expul-

15. Bernard VINCENT, «Les rumeurs de Séville», en Vivir el siglo de oro. Poder, cultura e historia en la época moderna, Salamanca, Universidad de Salamanca, 2003, pp. 165-178. 
sión. Es prueba al menos de su eficacia argumental. En su carta usted da varios ejemplos de ellos, incluso el del sermón del Patriarca Ribera en la seo de Valencia, el 27 de septiembre de 1609. Creo que en cuanto a la interpretación de este mito, nada ya nos separa.

Nadie hoy va a sostener seriamente que hubo unanimidad entre los cristianos viejos a favor de la expulsión de los moriscos. Las expresiones desfavorables a la medida fueron numerosos y impecablemente sintetizadas en el Diálogo de consuelo por la expulsión de los moriscos de España que escribió el zaragozano Juan Ripol en $1613^{16}$. Y si los historiadores del XIX han desarrollado ampliamente la idea de la aversión unánime, pocos los han seguido luego, salvo quizás hace ya años Earl Hamilton. Lo que sí merece un amplio debate es su concepto de la tendencia (o de la opinión) moderada existente en la sociedad española mayoritaria, de la cual da en su carta abierta una formulación parcialmente distinta al de El problema morisco.

Varias aclaraciones suyas son importantes. Me alegra leer su afirmación de que "nadie era allí lo que se dice ‘favorable' a los moriscos ni argüía el principio de libertad religiosa". Ésta se aleja de la frase siguiente de El problema morisco que me había dejado perplejo: "para estos racionalistas (la secta de los políticos) siendo los moriscos tan necesarios para la prosperidad de los reinos españoles, no sólo es absurdo expulsarlos, sino que deberían ser dejados en libertad de conciencia, anulando así el problema político y reduciendo a la esfera individual su aspecto religioso" ${ }^{17}$. Del mismo modo todo lo que usted desarrolla al final de la carta sobre el erasmismo avant la lettre pone fin al malentendido nacido con mi evocación en El río morisco de la teología de la liberación. Finalmente me complace su rechazo de "toda imagen de la opinión moderada a modo de un partido público de nuestros días", añadiendo no haber tenido nunca la menor sospecha de deber dar explicaciones sobre algo tan obvio. Le pido disculpas, pero el vocabulario empleado en El problema morisco me pareció rozar a ratos lo anacrónico (p. 118, un núcleo central de lo que cabe llamar opinión moderada; p. 121, la campaña moderada; p. 128, un grupo en que militaban los obispos de Segorbe $u$ Orihuela...). Había necesidad de precisar este punto fundamental que nos hace de todas formas preguntarnos si el concepto de opinión pública es válido para épocas tan remotas. No voy a entrar en los detalles porque esta enorme cuestión nos llevaría muy lejos, pero debemos tenerla presente en la mente.

Y pensándolo bien, su última definición de la opinión moderada no me convence todavía totalmente. Es para usted un discurso político que tiene cabezas rectoras contando "con una medida de eco o respaldo colectivo y que la literatura respaldaba con amplia resonancia". Eso me parece demasiado bonito porque implica unos directores de orquesta disponiendo de una red eficaz

16. Santiago TAlavera y Francisco Javier Moreno DíAz Del CAMPO, Juan Ripol y la expulsión de los moriscos de España, Zaragoza, Institución Fernando el Católico, 2008.

17. Francisco MárQuez VIllanueva, op. cit., p. 120. 
que difunde sus ideas. Algo que no veo. Y más arriba he indicado que la literatura no tenía, por desfases cronológicos, la eficiencia práctica que le atribuye. Lo que me molesta es la concepción de una vía, o tendencia, u opinión, o corriente organizada. Sería partidario en el actual estado de la investigación del uso del plural: opiniones moderadas que ciertamente tienden al mismo fin, el mantenimiento de los moriscos en España, pero que no llegan a constituir digamos un frente capaz de hacerse oír por el monarca y su valido. Los partidarios de la "opinión moderada" actúan de manera desordenada en función de preocupaciones e intereses distintos. Por ejemplo, no sigo a Trevor Dadson cuando ve una clara pugna en los años precedentes a la expulsión en el Consejo Real entre un sector eclesiástico-militar y un sector nobiliario ${ }^{18}$. Las cosas no son tan nítidas. Es necesaria la realización de un estudio minucioso de todos los debates del Consejo para saber si las alianzas son duraderas u ocasionales, si son o no son socialmente homogéneas, cuáles son los argumentos esgrimidos a favor y en contra de la expulsión, en qué condiciones estos argumentos están presentados. Y espero su próximo libro y particularmente su análisis de la obra de Pedro de Valencia. Ve usted una relación entre la postura de Manuel Ponce de León y el pensamiento del humanista extremeño. ¿Hay más conexiones? ¿Qué difusión ha tenido el Tratado de los $M o r i s \cos ^{19}$ ? De momento creo que las opiniones moderadas no constituyen una tendencia o una corriente. Y posiblemente esta debilidad constituyó un factor importante de su fracaso.

Me permitirá al final volver sobre su conclusión acerca del mito de la unanimidad. Ve a la expulsión "como obra de una archiminoría de eclesiásticos y políticos en ejercicio del poder". Primero, si no hay unanimidad entre las elites del poder sí podemos afirmar que los partidarios de la expulsión eran, entre ellas, numerosos. No digo mayoría porque no lo sé, pero sí numerosos. A este respecto el análisis que han hecho Manuel Fernández Chaves y Rafael Pérez García de los debates internos del ayuntamiento sevillano son particularmente reveladores para el nivel local. Las reticencias a la expulsión son fuertes, pero no todos los ediles las comparten ${ }^{20}$. Habrá que multiplicar las monografías para extraer una visión de conjunto.

Los artífices de la decisión de la expulsión, muy preocupados por la reputación de la monarquía, se sabían respaldados por gran parte de la sociedad

18. Trevor J. DADSON, «Official Rhetoric versus Local Reality: Propaganda and the Expulsion of the Moriscos», en R.J. PYM (ed.), Rhetoric and Reality in Early Modern Spain, Londres, Tamesis, 2006, pp. 1-24. Es un trabajo que usted cita en la nota 28.

19. Tengo que reconocer mi deuda con un trabajo pionero raramente citado en los estudios moriscos: Chantal Collonge, «Reflets littéraires de la question morisque entre la guerre des Alpujarras et l'expusion (1571-1610)», Boletín de la Real Academia de Buenas Letras de Barcelona, XXXIII, 1969-1970, pp. 137-243. Es casi un libro donde por primera vez vi analizado el Tratado de los moriscos de Pedro de Valencia. Ver concretamente pp. 213-232.

20. Manuel Fernández Chaves y Rafael Pérez García, En los márgenes de la ciudad de Dios: moriscos en Sevilla, Valencia, Universidad de Valencia, Universidad de Granada, Universidad de Zaragoza, 2010 (Biblioteca de Estudios Moriscos, 6). 
española. Una de las asignaturas pendientes de los estudios moriscos es el del sentimiento popular de los cristianos viejos y de los moriscos. Por algo éstos han preferido masivamente ir al Norte de África y no quedarse en Francia o en Italia. Por algo Tiopieyo ha convencido con la probable presión de convecinos a su hermana y a su sobrina para tomar aquel camino. No en vano los cristianos viejos han escuchado las imprecaciones de sus sacerdotes a lo largo de los años. No en vano han circulado los rumores más extravagantes sobre la conspiración y la felonía de los moriscos. Las relaciones entre unos y otros, en el pueblo, podían ser buenas pero en cualquier momento podía estallar el odio popular.

Es tiempo de poner un punto provisionalmente final a estas líneas. Digo provisionalmente porque espero que pronto tengamos otras ocasiones de precisar nuestras ideas y de enriquecer nuestras perspectivas. Formulo deseos para que se repitan pronto, en cualquier lugar del mundo, los desayunos de Bielefeld. No vamos a eliminar de un golpe nuestras diferencias, pero tampoco hay necesidad. Le agradezco, querido don Paco, sinceramente todo lo que continuamente me está desvelando. Le doy un fuerte abrazo. 